INDEPENDENT JOURNAL OF MANAGEMENT \& PRODUCTION (IJM\&P)

http://www.ijmp.jor.br

v. 12, n. 7, September-October 2021

ISSN: 2236-269X

DOI: 10.14807/ijmp.v12i7.1457

\title{
CONTRIBUTIONS OF INTERPERSONAL CONFLICT MANAGEMENT ON PERFORMANCE OF GOVERNMENT HOSPITALS IN NIGERIA
}

\author{
Kelechi Johnmary Ani \\ Alex Ekwueme Federal University, Nigeria \\ E-mail: kelechi.ani@funai.edu.ng \\ Chigozie Onu \\ Nnamdi Azikiwe University, Nigeria \\ E-mail: asiano.jc@gmail.com \\ Ijeoma Genevieve Anikelechi \\ Nnamdi Azikiwe University, Nigeria \\ E-mail: ijeomakc@gmail.com
}

Submission: 9/29/2020

Accept: 10/26/2020

\section{ABSTRACT}

This study investigated the place of interpersonal conflict management on performance of government hospitals in Nigeria and specifically. The purpose is to ascertain how collaborative approach of interpersonal conflict management affect mortality rates reduction in government hospitals and investigate if avoidance technique in conflict management improves the working relationships in the government hospital within Nigeria. The study adopted survey research design and was conducted in National Hospital Abuja, and University of Nigeria Teaching Hospital (UNTH) Ituku/Ozalla, Enugu State, Nigeria. The study population is 1629 , which includes all health professionals employed in selected public- owned teaching hospitals. A sample size of 312 was drawn from the population. The study used descriptive statistics (frequency, charts, tables and simple percentage) to calculate, analyse, show or summarize responses to the research questions. The hypotheses were tested using ordinal logistic regression. Findings showed that collaborative approach has significantly contributed in reducing mortality rates in government hospitals in Nigeria, and avoidance as a means of interpersonal conflict management helped improve the working relations of selected government hospital staff in Nigeria. 
DOI: 10.14807/ijmp.v12i7.1457

The study recommended that they should be improved communication, and collaboration between management, clerks, nurses, doctors and workers representatives in running the affairs of the hospitals. Again, conflicting tendencies should always be avoided by workers for more efficient, peaceful, coordinated and minimal conflicts in working environment within the healthcare industry.

Keywords: Interpersonal Conflict; Conflict Management; hospital; nurses \& doctors

\section{INTRODUCTION}

Interpersonal conflict is a form of conflict that manifests when the goals, ambitions, interests and purpose of a person clashes with another. Interpersonal conflict occurs between two or more individuals. Many forms of individual differences lead to interpersonal conflict, including personalities, culture, attitudes, values, perceptions, and the other differences.

While it is a minor source of misunderstanding, it can escalate in some work place, especially when it affects people of the same rank. On the other hand, interpersonal conflict is sometimes necessary for better performance within the work environment of public and private sector, especially when used as a tool for corrections. Interpersonal conflict is considered psychologically and socially healthy if it provides it encourages constructive opposition to the status quo and provides conditions for social chances, transformations and optimal results. Therefore, interpersonal conflict is a human culture and a sign of a healthy organization, to a reasonable point, provided it does not undermine productive output.

The departure or escalation from the point of positive manipulation calls for management, to avoid escalation. Conflict, per se, is not necessarily good or bad but an inevitable feature of organizational life and should be judged in terms of its effects on performance (Mullins, 2005).

This is a realistic view of hospital because interpersonal conflict is a common occurrence, particularly at the clinical services, administrative, management, diagnostic services and other specialist in various departments. However, rather than being destructive, the conflict may actually be used to redesign more effective and efficient productivity and service systems.

Interpersonal conflict in the hospital arises due to a variety of factors. These factors include managerial clashes of interest, individual differences in goals, expectations, values, proposed courses of action, and suggestions over how to best handle a critical health situation. 
DOI: 10.14807/ijmp.v12i7.1457

Managerial clashes of interest, individual differences in goals, expectations, values, proposed courses of action, and suggestions about how to best handle a situation are unavoidable.

Interpersonal Conflict in the health sector has been due to various causes which include poor remuneration and working conditions for workers; inadequate health facilities; lack of medical infrastructure; and among others. The basis of conflict between health workers is often attributed to divergent opinion. An Employee may perceive other employees as lazy, and uncooperative, others perceive the other as exploitative. The prevalence of interpersonal conflict in public hospitals seems to be one of the distinctive features of their operation (Dann \& Hornsay, 1986).

Four possible reasons for the heightened interpersonal conflicts in the public hospital, either in isolation or collectively include; interdependence, hospital environment, rewards, status and stigma. Dann and Hornsay (1986) maintains that the prevalence of interpersonal conflict in public hospitals seems to be one of the distinctive features of their operation.

Which consequently results into various types of interpersonal conflict such as task conflict (disagreements among group members about the content of tasks being performed, including differences in viewpoints, ideas, policies and opinions” (Jehn, 1997), relationship conflict (interpersonal incompatibilities among persons in a group, which may include personality differences), horizontal conflict (between employees working at the same hierarchical level) and vertical conflict (between employees working at different hierarchical levels).

It should be noted that interpersonal conflict is a common occurrence in hospitals, particularly at the clinical services, administrative, management, diagnostic services and other specialist units and departments within the hospital. But, rather than being destructive, the conflict may actually be used to redesign more effective and efficient productive and service delivery process.

However, since interpersonal conflicts is inevitable in government hospitals, management of interpersonal conflicts should be a focal point for every healthcare institution. Among the basic management problems in the government hospital in Nigeria is the crisis of interpersonal conflicts. Thus, the challenge for hospital management is how to carry-out effective administration in their environment so as to maximize efficiency and minimize waste because productivity suffers when unhealthy interpersonal conflict persists. 
DOI: 10.14807/ijmp.v12i7.1457

For many years, conflict management researchers tried to determine how interpersonal conflict could be reduced and resolved within an organization. The implicit assumption was that interpersonal conflict can be detrimental to the organization and that it would be beneficial to reduce or eliminate conflict.

This study asked questions that include what causes interpersonal conflict in government hospitals in Nigeria? And how does interpersonal management affect efficient performance in the hospital? Studies handling personal conflict in Egypt Elsayed-Elkhouly (1996) and United States, Africa, and the Gulf States (Greer \& Kleef, 2008) but scarcely has any examined interpersonal conflict management in government hospital in Nigeria. Thus, to fill this gap in scholarly literature, the study investigated the contributions of interpersonal conflict management on performance of government hospitals in Nigeria. However, the specific objectives are to:

1. ascertain how collaborative approach of interpersonal conflict management affect mortality rates reduction in government hospital; and

2. investigate if avoidance technique of interpersonal conflict management improves the working relationships in the government hospital in Nigeria.

Therefore, the questions are:

1. How does a collaborative approach of interpersonal conflict management help reduce mortality rates in government hospital in Nigeria? and

2. Does avoidance technique of interpersonal conflict management help in improving the working relationships in the government hospital within Nigeria?

The following hypotheses therefore guilds the study:

1. Ha: Collaborative approach of interpersonal conflict has significantly enhanced the mortality rates reduction in the selected government hospitals; and

2. Hi: Avoidance technique of interpersonal conflict management has improved the working relationships in the government hospitals in Nigeria.

\section{MATERIALS AND METHODS}

This study used survey research design. This method permits for the collection of data from a relatively few respondents and guarantees the generalization of findings to larger 
respondents. It is considered appropriate because it deals with large population of people/respondents with different characteristics.

The study was conducted in two tertiary hospitals namely; National hospital Abuja, and University of Nigeria Teaching Hospital (UNTH) Ituku/ Ozalla, Enugu State, Nigeria. Tertiary hospitals are major hospitals that are publicly-owned, either by the federal or state government, and they provide tertiary care from specialists, after referral from primary care and secondary care centers.

They usually have full services including paediatrics, obstetrics, general medicine, and gynaecology, as well as various branches of surgery, psychiatry and sophisticated intensive care facilities. The study population includes all health professionals employed in selected public-owned teaching hospitals in Nigeria. The health professionals are Doctors, Nurses, Medical Laboratory Scientists, Pharmacists, Radiographers, and Physiotherapists. The total population of health professionals in the two selected hospitals is 1,629 persons. Having applied the Cochran sample size derivation statistic, the value derived was three 312 .

The study used descriptive statistics (frequency, charts, tables and simple percentage) to calculate, analyse responses to the research questions. The hypotheses were tested using ordinal logistic regression. This is justified on the fact that ordinal logistic regression is used to predict an ordinal dependent variable given one or more independent variables. The decision rule is Reject the null hypothesis (Ho) if P-value $<0.05$ and Do not reject if otherwise.

\section{DISCUSSION}

\subsection{Concept of Interpersonal Conflict}

Interpersonal conflicts manifest between people who have clashing interests, goals and ambitions. It is the process through which a person or a group frustrates another from obtaining its desired result. Interpersonal conflicts are conflicts that affects at lkeast two living beings, hence it is a form of conflict that occurs between two or more individuals that work together in groups or teams within an organisation.

Schramm-Nielsen (2002) defines the concept of interpersonal conflict as a state of serious disagreement and argument about something perceived to be important by at least one of the parties involved. Elsayed-Elkhouly (1996), state that many individual differences lead to interpersonal conflict, including personalities, culture, attitudes, values, perceptions, and the other differences. 
DOI: 10.14807/ijmp.v12i7.1457

To Rahim (2001), it is the conflict among members of a group or sub-group as regards the carrying out of their goals, tasks and procedures to be used. Henry (2009) conceptualized interpersonal conflict as a dispute that occurs when interests, goals or values of different individuals or groups are incompatible with each other. It is the most common and problematic types of conflict experienced in work place (Wall \& Callister 1995).

Interpersonal conflict may include rude behavior and contentious disagreement. As noted, interpersonal conflict has long been considered a stressful job demand and as such it should positively influence job strain according to the demands-control model, which reveals that " work load demands, conflicts or other stressors places the individual in a motivated or energized state of 'stress',', and unless the individual can somehow take action to cope with the stressor, the unreleased energy induced by job stressors will manifest itself internally, producing distress and strain.

Interpersonal conflict includes task and relationship conflict (Jehn, 1997). This view of interpersonal conflict proposes that both types of interpersonal conflict are distinct, based on the differing conceptual relationships that each is expected to have with outcomes. However, the two types of conflict perceptions are interrelated, such that a group with many relationship conflicts may also have a high number of task conflicts and vice versa. Task and relationship conflicts can also share some conceptual overlap, as each type of conflict may affect the other. Task conflict may turn into relationship conflict if perceived as a personal disagreement. Misattributions about viewpoints or opinions could lead an individual to assume that his or her competence is being challenged and relationship conflict might result, especially when one partner is suffering from complex or the other is highly tempramental.

Interpersonal conflict can be seen as a constructive force and in certain circumstances it can be welcomed or even encouraged (Weihrich, 1992). The absence of interpersonal conflict may indicate autocracy, uniformity, stagnation, and mental fixity, while the presence of interpersonal conflict may be indicative of democracy, diversity, growth, and self-actualization (Pondy, 1992). Tjosvold (1998) complements this statement arguing that interpersonal conflict is not the opposite of cooperation but a mechanism that allows perceiving benefits of cooperative work. Butler (1973), state that interpersonal conflict is ubiquitous, not necessarily dysfunctional and can be required to defy people to perform and stimulate progress. In context of this study, the researchers defined interpersonal conflict as inherent disagreement in hospital as a result of clash in goals and interests among staff. 
DOI: 10.14807/ijmp.v12i7.1457

\subsection{Sources of conflict}

Sources of interpersonal conflict as identified by Chinweuba (2006) to include:

Organizational Structural Factors: which deals with factors in the organization such as the size and complexity of functions of the organization, remuneration of reward system and level of motivation from organization, which determine to a great extent the presence or otherwise as well as level of conflict one may experience in the organization when there is differential power allocation and asymmetrical interdependence among members. Across Nigerian health institutions, the competition between the hierarchical position of doctors and other health workers drives conflict.

Anti-Authority: deals with some people in an organization, who due to certain factors like maladjusted personality or envy; feel marginalized or oppressed by the administration. They perceive impersonal bureaucratic behaviours negatively and as such they gang up with some other members who would often deliberately negate the prescriptions of those in authority.

Opposing Personalities: naturally, there are personality diversities in the work place, including health institutions. While some people can crack jokes easily and almost always, there are some people who do not withstand jokes or teases and easily take offence each time one is made on them, hence people who are quiet and reserved are usually in conflict with those who are radical and extravagant in the healthcare industry. Their quarrels sometimes emanate from the use and generous sharing of medical protective equipment with other healthcare practitioners.

Generation Gap: This is a term used to explain the situation where people seem to resist new methods, ideas, values and technological innovations and would rather maintain the status quo. This situation resulting from what is regarded in sociology as cultural lag is attributed to 'change in norms and way of life', which is felt in almost all facets of life. This often generates some identity crises among people which can give rise to one type of conflict or another.

For instance, the changing nature of dressing amongst health practitioners, who trained abroad before independence, those who trained after independence and the younger generation of health workers as well as the culture of using personal protective kits differ and often generates conflict. When the personality background of a young medical officer is resistant to change which the superior wants from him or her, then conflict escalates. 
DOI: 10.14807/ijmp.v12i7.1457

Prejudices: these include the favourable or unfavourable attitudes of an individual to another or other persons. This usually leads to misattributed conflict resulting to discrimination, antipathies and hostile attitudes to others. A popular example is the negative and prejudice based attitude of some non-graduate nurses to graduate nurses.

Authoritarian Rule: emanates from a situation where some bureaucratic heads handles the workmen or subordinate as machine and makes poor judgments, subscribing rarely to inbetween judgments. The boss here, is highly intolerant of ambiguity and things less of human feelings. His decision may seem to favour some people in the organization who would develop the attitude that "we own here" or are king makers in the healthcare establishment. This creates division among the people in any organization, particularly when there is suspected uneven distribution of rewards.

Frustration: Poor motivation or non-motivation of people in a health care institution can lead to frustration which in turn, can lead to conflict.

Aggressive Personality: There are people that are aggressive in nature and do not accommodate challenging situation. When they suspect any challenge they set out traps to let a casualty into their net so that they can fight you.

Envy and Jealous: This type of conflict is common between persons that used to be of equal rank but one later becomes promoted to a higher cadre like head of a department, principal of nursing school. The others feel somewhat uncomfortable and becomes jealous of the incumbent.

Adebile and Thompson (2012) also identified sources of interpersonal conflict as follows:

(i) Disagreements between persons that occur when one of the person's experiences stress;

(ii) Problems ensuing from role conflict, a situation that happens when there is a clash over an individual function in the organization;

(iii) Clash of power tussle between individuals and between groups over the accomplishments of set objectives;

(iv) Misunderstandings leading to disagreements over other people’s problems and manner of solving these problems;

(v) Improper communication and interaction breakdowns as a result of the interdependence requirements for collaboration; and 
(vi) Pressures from external forces outside the organisation that results in breeding internal pressures as the organisation tries to adjust to these changes.

It should be noted that sources of conflict can either be personal or organizational as some conflicts are related to individuals having incompatible goals while others are related to the way an organization is structured or managed. Personal conflict can be traced to differences in individual's value, perceptions or culture while organizational sources of interpersonal conflicts can be traced to the following:

Goal Incompatibility: This is said to be the source of many conflicts because of the fact that many departments within the healthcare industry focus on different tasks and functions.

Scarce resources: Interpersonal conflict is almost automatic anytime there is scarcity in health equipment and protective or surgical kits. Conflicts over scarce resources are exceedingly common in organizations. Where the scarcity is absolute (the resource level cannot be enhanced) it is very difficult to manage interpersonal conflicts. Uncertainty: Due to frequent changes in the healthcare environment leading to uncertainty which makes it difficult for managers to have a clear direction, many are forced to adapt to "rapidly shifting environmental constraints" and are, therefore, under pressure which invariably leads to conflict as departments and employees within the organization deal with changing goals.

Personality differences: Some people have difficulty in getting along with each other in the health institutions. This is purely a psychological problem and it has nothing to do with their job requirements or formal interactions.

Perceptions: Varied backgrounds, experiences, education and training result in individuals developing different perceptions of similar health realities. The result being an increase in the likelihood of interpersonal conflict.

\subsection{Theoretical Framework}

This study is based on cognitive model of interpersonal conflict management. Hammond (1965) proposed the interpersonal conflict theory to explain the nature, source, and resolution of disagreement or “cognitive conflict” between parties performing tasks. Cognitive conflict management represents differences in how parties conceptualize the solution to a problem. For instance, different parties may have different policies for solving a problem in terms of the information they rely on. 
DOI: 10.14807/ijmp.v12i7.1457

Inconsistency in how parties apply their judgment policies can also lead to disagreement. Thus, according to interpersonal conflict management theory; parties striving to make a joint judgment on the same task could engage in conflict because they disagree in principle (in that they have different policies for how to solve a given problem) and/or in practice (in that they are inconsistent in the application of their policies).

Applying this theory, in government hospitals, reveals that conflict is inevitable because of the diverse nature of the working environment, sometimes the result is either positive or negative change. The conflicting classes in the hospital, the management, and the workers (the proletariats) are always interested in gain-maximization, which leads to struggle that results in interpersonal conflict. This theory suggest that interpersonal conflict could be resolved by engaging the parties closely and using corporative means until the conflicting parties reach an acceptable joint response (joint agreement) towards peace.

\subsection{Empirical Review}

A number of researchers have attempted to examine the effect of interpersonal conflict management on staff performance in hospitals. For example, Mukolwe, Korir, Buyeke, Wafula\& Musyoki (2015) investigated the effect of interpersonal conflict on organizational performance of selected hotels in Kisii town. This was carried out by investigating the types, outcomes and strategies for managing interpersonal conflict.

The study employed both descriptive survey and explanatory research designs. It targeted a population of 368 employees. A sample size comprising 194 employees were selected using stratified random sampling. Questionnaires were used to collect data which were validated through a pilot test, while reliability was measured using the Cronbach's Alpha. The data was analyzed using descriptive and inferential statistics and multiple regression was used to test the hypotheses.

The results indicated that interpersonal conflict strategies, relationship conflict and task conflict significantly affect organizational performance respectively, while outcomes of interpersonal conflict do not significantly affect organizational performance.

Skjørshammer (2002) studied conflict and conflict management in a Norwegian hospital. 29 persons throughout the hospital were interviewed, and they have various professional backgrounds in medicine, nursing or other ancillary support professions. The gender distributions followed traditional dividing lines in hospitals. Age-wise, participants 
DOI: 10.14807/ijmp.v12i7.1457

represented a wide distribution from newly trained nurses or physicians to others close to retirement.

General hospital leadership and all hospital departments were represented on various managerial and professional levels. The interviews consisted of open-ended questions related to the participants' experience with conflict (conflict behaviour, extent of conflicts, perception and attribution of conflicts) and cooperation among peers and other professional groups. Data was analyzed according to a grounded theory approach, supported by the use of the NUD: IST software.

Validation was carried out by presenting the research findings at various seminars. The analysis revealed that when there is outbreak of conflict, professionals use three major approaches to handle the situation. They include avoidance, force, negotiation and compromise, usually in that order. Regardless of professional background, department or hierarchical level, all participants refer to the prevalent use of avoidance. They perceive that there are few opportunities for addressing conflicts.

Avoidance as a way of handling conflict is expressed through different behavioral styles that include silent withdrawal after a confrontation, keeping the issues and feelings to oneself, and actively talking with peers or own reference group (hallway gossip). This is related in recent study in scope of variable but differs in methods and area of study.

A study by the Chartered Institute of Personnel Development (CIPD) (2008), in association with Business Psychology Consultancy on leadership and conflict management at work place, revealed that $44 \%$ of respondents said that warring egos and personality clashes are the most commonly cited causes of conflict as far as human resource practitioners are concerned; while $30 \%$ of the respondents said it is poor leadership from the top; on the other hands, $21 \%$ of the respondents said it is inadequate line management, and $17 \%$ linked conflicts to weak performance by management.

Al- Hamdan (2009) worked on conflict management styles used by nurse managers in the Sultanate of Oman. 335 questionnaires were distributed to all nurse managers working in the three management levels from nine referral hospitals in Sultanate of Oman, and 271 were returned, with a response rate of $86 \%$. The results showed that nurse managers in Oman used all five conflict management styles with integrating style as the first choice.

The second in use was compromising which means finding a solution that will at least partially satisfy everyone, everyone is expected to give up something to resolve conflict. 
DOI: 10.14807/ijmp.v12i7.1457

Obliging was the third skill they used, which means willingness to do a service or kindness. The nurse managers also used dominating skill which means having a commanding influence on, exercise control over. The last in their list was avoidance skill, which means keeping away from or stop oneself from doing (something).

Another study was conducted by Kaitelidou et al (2012) on conflict management and job satisfaction in Pediatrics Hospital in Greece. The study was aimed at assessing the major causes of conflict and also its management. 286 participants were used; a five-part questionnaire, specific for conflicts in hospitals was administered to participants, which include $37 \%$ as physicians and $63 \%$ other personnel.

Result showed that as far as choice of strategy in conflict management is concerned, avoidance was found to be the most frequent mode chosen. (Avoidance means keeping away from or stop oneself from doing (something) that will lead to conflict. Accommodation was the lowest frequent mode. Accommodation means willingness to meet the needs of others at the expense of the person's own needs. Organization problems were the main issue creating conflicts since $52 \%$ of nurses and $45 \%$ of physicians agreed that receiving direction from more than one manager may lead to conflicts.

Lawrence and Lorsch (1967) carried out a study using 118 nurses (25\% managers). They examined the role of perceived available support in buffering the negative effects of intragroup conflict. Perceived available support was defined as the amount of support that individuals feel is available when a need arises. The result of the study showed that nurses who felt a high degree of support from their managers were able to cope more effectively with conflict in their workplace.

These findings emphasize the importance of managers' support when dealing with conflict. In summary, managerial support to nurses is a key factor in a positive work environment, if this support is not available; nurses feel betrayed and their work environment are affected. Nurses rely on their managers to be a source of formal information and advice that helps them cope more effectively when attempting to resolve conflict.

In a study using the Thomas - Kilmann Conflict Mode instrument to measure the five conflict resolution styles of 201 managers (99 males and 102 females) in both situational roles. Sex differences were examined along with hierarchical rank. Both genders tend to handle conflict more competitively at work than at home, and used the accommodating style more frequently at home than at work. At home, low-level women managers were more willing to 
DOI: 10.14807/ijmp.v12i7.1457

collaborate and less willing to avoid conflict than at work; men managers, who were less likely to compromise at home than at work.

Chukwuemeka, Ugwu, Enugu and Igwegbe (2012) conducted a study on industrial conflict and management in some local government areas in Enugu state. The study recorded that $66.7 \%$ respondents accepted that funding is a contributing factor to organizational conflicts. 30.7\% respondents said that the leadership type is autocratic and ineffective, while $30.3 \%$ respondents said that employee participation in decision making is not encouraging. As a flaw, the study emphasized only on the internal causes of conflicts, while neglecting the external causes such as government's poor economic and industrial policies, economic mismanagement and unequal distribution of power in organisation.

It could be observed that most of the Nigerian studies were carried out within the period 2010 to 2013 which shows a gap in period. The current study is will fills the gap and accommodate the recent developments. The most profound knowledge gap which this study has filled is in the area of examining the contributions of interpersonal conflict management on performance of government hospitals using current and expanded empirical evidence from Nigeria.

\subsection{Management of Interpersonal Conflict in Hospitals}

\subsubsection{Collaborating Method}

This conflict management method involves people undermining their weaknesses as well as differences and then teaming together to work on problems until they have attained mutually satisfactory solutions. This approach assumes that people will be motivated to expend the time and energy for such problem-solving activity.

The collaborating method deals with high assertiveness and high cooperation and is focused on working together. Here, the needs of all people involved in conflict management process are met. It is therefore most appropriate conflict handling style when the issue at stake is important to all the parties involved in the conflict, and when the issues are too important to be compromised, as well as when emerging perspectives and gaining commitment are needed.

It is highly used when improving relationships in the workplace, when a variety of viewpoints is brought together to get the best solution and when there have been previous conflicts in the group. Skills applied include identifying concerns, listening to others, weighing inputs, and nonthreatening confrontation. 
DOI: 10.14807/ijmp.v12i7.1457

Collaboration is the most desirable approach in resolving a conflict. It is an assertive cooperative approach that allows individuals to be creative and to find a solution that satisfies all concerns and goals to be achieved.

Collaboration is viewed as the opposite of avoidance and competition. The goal is for both parties to win. The problem solving process continues until all individual is satisfied with the resolution. Although this process is growth producing, it takes a considerable amount of time, (Kelly, 2006).

Collaborating is also the pooling of individual needs and goals toward a common goal. Often called "win-win problem-solving,". Collaboration requires assertive communication and cooperation in order to achieve a better solution than either individual could have achieved alone. It offers the chance for consensus, the integration of needs, and the potential to exceed the "budget of possibilities" that previously limited our views of the conflict. It brings new time, energy, and ideas to resolve the conflict.

\subsubsection{Avoidance and other Approaches}

The avoidance method of conflict management is suitable when the issue at stake is of low importance to reduce tension. Skills applied in avoidance include: withdrawal, step aside, ability to leave things unresolved, and sense of timing It should be noted that the avoidance style of conflict management by nurses predicted stress with peers and problems with their superiors.

Avoidance has also been associated with increased levels of work stress, which has been linked to negative patient outcomes; such as medication errors, intravenous errors, and reduced quality and efficacy of care. It is worthy of note that the avoiders evade conflict entirely and sometimes creates another cycle of conflict by that action.

This style is typified by delegating controversial decisions, accepting default decisions and not wanting to hurt anyone's feelings. It can be appropriate when victory is impossible, when the controversy is trivial or when someone else is in a better position to solve the problem.

However, when controversial decisions are made on a life threatening situation and it is integrated with avoidance, the ultimate result will be increased mortality, which undermined to manifest destiny of men on earth. other preventive measures to interpersonal conflict include:

a) Goal structure: Goals should be clearly defined and the role as well as contribution of each unit towards the organizational goal must be clearly identified. All units and 
the individuals in these units must be aware of the importance of their role and such importance must be fully recognized.

b) Reward System: The compensation system should be such that it does not create individual competition or conflict within the unit. It should be appropriate and proportionate to the group effort and reflect the degree of interdependence among units where necessary.

c) Trust and communication: The greater the trust among the members of unit, the more honest and open the communication among them would be. Individuals and units should be encouraged to communicate openly with each other so that they can all understand each other, understand each other's problems and help each other when necessary.

d) Co-ordination: Co-ordination is the next step to communication. Properly coordinated activity reduces conflict. Wherever there are problems in co-ordination, a special liaison or human resource office should be established to assist such coordination.

Within hospitals, the five-style paradigm of conflict management (Blake \& Mouton, 1964) is most frequently used when explaining how professionals go about managing behaviour and events in the treatment process. This typology was used in a study of negotiation strategies in a U.S. hospital, extending the model by adding alliance formation” (coalition building) and "hierarchy" (involvement of higher level) to the number of behaviour strategies.

However, a survey study of intensive care units in Norwegian hospitals, using the same typology except for "alliance formation”, concluded with only three meaningful strategies: compromise, confrontation and problem solving. In a study of Swedish nurses in medical and surgical wards, confirmed that nurses use these three strategies, in addition to "alliance formation”, in negotiating with physicians.

In the "two-style model" of conflict management formulated by Deutsch and Coleman (2000), conflict behaviour is understood as resulting from either a "competitive" approach/goal- orientation or a "cooperative" approach/goal-orientation on the part of the participants and not as a choice between "self-" or "other" orientation. This model has been used within hospital research on conflict, albeit to a much lesser extent than the five-style paradigm. 
Research exploring the utility of this approach has focused exclusively on the leaderemployee relationship in hospital institution and not on the lateral inter-professional relationships. Tjosvold (1998) in his study on the relationship between leaders/ managers and physician/ nursing administrators/ staff employees, concluded that there is a definite advantage to work productivity and promotion of quality care, when participants emphasized their cooperative goals and reduced their competitive ones.

\section{RESULTS}

Questionnaire Return Rate: 210 questionnaires were distributed to respondents in UNTH and 199 was returned with a return rate percentage of 95\% while 102 questionnaires were distributed to the staff of National Hospital Abuja and 93 were returned with a corresponding return rate of $91 \%$.

\subsection{Analysis of the Returned Questionnaires}

The demographic characteristics of the respondents were carried out in this section with the application of tabled frequencies and percentages.

Table 1: Gender Distribution of the Respondents

\begin{tabular}{lrr}
\hline Gender & Frequency & Percentage \\
\hline Male & 142 & 49 \\
Female & 150 & 51 \\
\hline Total & $\mathbf{2 9 2}$ & $\mathbf{1 0 0}$ \\
\hline \multicolumn{2}{c}{ Source: Field Survey (2020). }
\end{tabular}

Table 1 reveals that $49 \%$ of the respondents are male while $51 \%$ of the respondents are female. This implies that there are more female employees among the respondents than male. This is attributed to the nursing dimension of the respondents, which constitutes of the female workers. It is a widespread fact that across Nigeria, the greater population of nurses are female with very few men amongst them.

Table 2: Age Distribution of the Respondents

\begin{tabular}{lrr}
\hline Age (In Years) & Frequency & Percentage \\
\hline $18-25$ & 30 & 10 \\
$26-35$ & 52 & 18 \\
$36-45$ & 190 & 65 \\
46 and above & 20 & 7 \\
\hline Total & $\mathbf{2 9 2}$ & $\mathbf{1 0 0}$ \\
\hline \multicolumn{2}{c}{ Source: Field Survey (2020). }
\end{tabular}

It can be clearly seen that table 2 reveals that of the respondents; 30(10\%) are between the ages of 18-25 years of age, 52(18\%) of the respondents are between $26-35$ years of age, 
DOI: 10.14807/ijmp.v12i7.1457

190(65\%) are between 36-45 years and 20 (7\%) between the ages of 46 years or above. This implies that greater number of the respondents are within 36-45 years age bracket.

Table 3: Respondent Years of Working Experience

\begin{tabular}{lrr}
\hline Working Experience & Frequency & Percentage \\
\hline $1-3$ & 12 & 4 \\
$4-6$ & 93 & 32 \\
6 years and above & 187 & 64 \\
\hline Total & $\mathbf{2 9 2}$ & $\mathbf{1 0 0}$ \\
\hline \multicolumn{2}{r}{}
\end{tabular}

Table 3: Statistically shows that only 12(4\%) of the respondents (representing twelve persons) have 1-3 years of working experience. The table shows that 93(32\%) of the respondents (representing 32 persons) have 4-6 years of working experience while 187(64\%) of the respondents (representing 187 persons) have working experience that is 6 years and above. This information showed that majority of the respondents has acquired good working experience and therefore should have a good knowledge of the study variables.

Table 4: Collaborative approach improves organizational efficiency of the hospital I am working for.

\begin{tabular}{lrr}
\hline Item & Frequency & Percentage \\
\hline Strongly Agree & 135 & 46 \\
Agree & 118 & 40 \\
Indifferent & 6 & 2 \\
Disagree & 22 & 8 \\
Strongly Disagree & 11 & 4 \\
\hline Total & $\mathbf{2 9 2}$ & $\mathbf{1 0 0}$ \\
\hline \multicolumn{2}{c}{ Source: Field Survey (2020). }
\end{tabular}

From table 4 11(4\%) of the respondents strongly disagree that collaborative approach improves organizational efficiency of the hospital they are working for, 22(8\%) disagree, 6(2\%) are indifferent, 118(40\%) agree and 135(46\%) strongly agree. This entails on the average that majority of the respondents agree that collaborative approach improves organizational efficiency of the hospital they are working for.

Table 5: Collaborative approach creates space for employees to be committed thereby reducing mortality rates

\begin{tabular}{lrr}
\hline Item & Frequency & Percentage \\
\hline Strongly agree & 74 & 25 \\
Agree & 199 & 68 \\
Indifferent & 8 & 3 \\
Agree & 6 & 2 \\
Strongly Agree & 5 & 2 \\
\hline Total & $\mathbf{2 9 2}$ & $\mathbf{1 0 0}$ \\
\hline
\end{tabular}

Source: Field Survey (2020). 
ISSN: 2236-269X

DOI: 10.14807/ijmp.v12i7.1457

The table 5 reveals that $5(2 \%)$ of the respondents strongly disagree that collaborative approach creates space for employees to be committed thereby reducing mortality rates, $6(2 \%)$ disagree, 8(3\%) are indifferent, 199(68\%) agree and 74(25\%) strongly agree. This entails on the average that majority of the respondents agree that collaborative approach creates space for employees to be committed thereby reducing mortality rates.

Table 6: In our hospital, avoidance means of interpersonal conflict management significantly

\begin{tabular}{lrr}
\multicolumn{3}{c}{ influences working relations among staff. } \\
\hline Item & Frequency & Percentage \\
\hline Strongly Agree & 135 & 46 \\
Agree & 118 & 40 \\
Indifferent & 6 & 2 \\
Disagree & 22 & 8 \\
Strongly Disagree & 11 & 4 \\
\hline Total & $\mathbf{2 9 2}$ & $\mathbf{1 0 0}$ \\
\hline
\end{tabular}

From table 6 11(4\%) of the respondents strongly disagree that in their hospital, avoidance means of interpersonal conflict management significantly influences working relations among staff, 22(8\%) disagree, 6(2\%) are indifferent, 118(40\%) agree and 135(46\%) strongly agree. This entails on the average that majority of the respondents agree that in their hospital, avoidance means of interpersonal conflict management significantly influences working relations among staff, 22(8\%).

Table 7: Regression Result for Hypothesis one

Dependent Variable: MR

\begin{tabular}{|c|c|c|c|c|}
\hline \multicolumn{3}{|l|}{ Method: Least Squares } & & \\
\hline \multicolumn{3}{|c|}{ Date: 11/02/20 Time: 11:56 } & & \\
\hline \multicolumn{3}{|l|}{ Sample: 1292} & & \\
\hline \multicolumn{3}{|c|}{ Included observations: 292} & & \\
\hline Variable & Coefficient & Std. Error & t-Statistic & Prob. \\
\hline $\mathrm{C}$ & 3.350808 & 3.400219 & 0.985468 & 0.3254 \\
\hline CA & -0.621192 & 0.032170 & -19.30944 & 0.0000 \\
\hline R-squared & 0.609384 & \multicolumn{2}{|c|}{ Mean dependent var } & 20.72614 \\
\hline Adjusted R-squared & 0.607750 & \multicolumn{2}{|c|}{ S.D. dependent var } & 81.27694 \\
\hline S.E. of regression & 50.90364 & \multicolumn{2}{|c|}{ Akaike info criterion } & 10.70601 \\
\hline Sum squared resid & 619292.2 & \multicolumn{2}{|l|}{ Schwarz criterion } & 10.73493 \\
\hline Log likelihood & -1288.074 & \multicolumn{2}{|c|}{ Hannan-Quinn criter. } & 10.71766 \\
\hline F-statistic & 372.8547 & \multicolumn{2}{|c|}{ Durbin-Watson stat } & 1.825809 \\
\hline Prob(F-statistic) & 0.000000 & & & \\
\hline
\end{tabular}

Source: Author's Computation Using E-views

Model Line: $\mathrm{MR}=\mathrm{bo}+\mathrm{b}{ }_{1} \mathrm{CA}+\mathrm{U}$

Regression Line: $\mathrm{MR}=3.350808$ - $0.621192 \mathrm{CA}$

Where; MR = Mortality Rates, CA = Collaborative approach and $\mathrm{U}=$ stochastic error term. 
ISSN: 2236-269X

DOI: 10.14807/ijmp.v12i7.1457

\subsection{Discussion of Results}

The regression result showed that collaborative approach (CA) yielded a negative value at the magnitude of -0.621192 . This entails that a $1 \%$ change in collaborative approach leads to a negative change in mortality rate by -0.621192 . This showed a negative causation between the two variables. It therefore confirms that adopting the collaborative approach reduces the level of mortality rates in selected hospitals in Nigeria.

The coefficient of determination showed that $61 \%$ variations in mortality rate of the selected hospitals is significantly influenced by the collaborative approach of interpersonal conflict management. The result shows also that collaborative approach of interpersonal conflict management is statistically significant with p-value of 0.0000 which is less than the critical value of 0.005 .

This compels the rejection of the null hypothesis (Ho) and then conclude that collaborative approach has significantly contributed in reducing mortality rates of selected government hospitals in Nigeria..

Table 8: Hypothesis two

\begin{tabular}{|c|c|c|c|c|}
\hline \multicolumn{5}{|c|}{ Dependent Variable: WR } \\
\hline \multicolumn{5}{|c|}{ Method: Least Squares } \\
\hline \multicolumn{5}{|c|}{ Date: $11 / 02 / 20$ Time: $12: 12$} \\
\hline \multicolumn{5}{|l|}{ Sample: 1292} \\
\hline \multicolumn{5}{|c|}{ Included observations: 292} \\
\hline Variable & Coefficient & Std. Error & t-Statistic & Prob. \\
\hline $\mathrm{C}$ & 0.851765 & 2.099805 & 0.405640 & 0.6854 \\
\hline AM & 0.802653 & 0.026506 & 30.28145 & 0.0000 \\
\hline R-squared & 0.793247 & \multicolumn{2}{|c|}{ Mean dependent var } & 17.32780 \\
\hline Adjusted R-squared & 0.792381 & \multicolumn{2}{|c|}{ S.D. dependent var } & 69.09749 \\
\hline S.E. of regression & 31.48439 & \multicolumn{2}{|c|}{ Akaike info criterion } & 9.745125 \\
\hline Sum squared resid & 236912.8 & \multicolumn{2}{|l|}{ Schwarz criterion } & 9.774044 \\
\hline Log likelihood & -1172.288 & \multicolumn{2}{|c|}{ Hannan-Quinn criter. } & 9.756776 \\
\hline F-statistic & 916.9663 & \multicolumn{2}{|c|}{ Durbin-Watson stat } & 1.654029 \\
\hline Prob(F-statistic) & 0.000000 & & & \\
\hline
\end{tabular}

Model Line: $\mathrm{WR}=$ bo $+\mathrm{b}_{1} \mathrm{AM}+\mathrm{U}$

Regression Line: WR $=0.851765+0.802653 \mathrm{AM}$

Where; WR = Working Relations, $\mathrm{AM}=$ Avoidance Means and $\mathrm{U}=$ Stochastic Error Term.

\subsection{Interpretation}


DOI: 10.14807/ijmp.v12i7.1457

The result showed that if other variables are held constant at zero, working relations is predicted to be at 0.851765 . The numerical coefficient of avoidance means is estimated at 0.802653. This implies that if avoidance means of interpersonal conflict management is used, working relations among the workers is improved by 0.802653 . The adjusted $\mathrm{R}^{2}$ which is the summary measure that tells us how well the sample regression line fits the data is 0.792381 .

This means that approximately, $79 \%$ of the variation in working relations was explained by changes in avoidance means. The remaining $21 \%$ was explained by variables not included in the model. The study rejects null hypothesis (Ho) and conclude that avoidance means of interpersonal conflict management helped improve the working relations of selected government hospitals in Nigeria.

This is in line with the study conducted by Kaitelidou et al (2012) on conflict management and job satisfaction in Pediatrics Hospital in Greece. Result showed that as far as choice of strategy in conflict management is concerned, avoidance was found to be the most frequent mode chosen.

It is noteworthy that conflict management involves decision making that ensures workplace peace, and occurs when there are unequal power relations. Conflict management can be achieved through openness, communication, temperament management, mutual respect and clear perspective on issues. Interpersonal conflict management is the means by which fair treatment and job satisfaction is enhanced in the hospitals.

Thus, the aim of interpersonal conflict management in the government hospitals is usually to ensure effective performance, qualitative healthcare delivery, hospital growth as well as peace and progress among various individuals and institutions in the hospital. Interpersonal conflicts are managed through avoidance and self-help.

Negotiation, dialogue, third party intervention, arbitration etc. are some of the ways to manage third party intervention in the work place. Interpersonal conflict if properly managed is a potentially positive and productive force for change that brings growth and development to hospitals and other organizations.

It would be recalled that performance of hospitals comprises the actual output or results of the healthcare institution in terms of ensuring the decrease in mortality rate and increasing and ensuring improved health of patients as the main output. Performance should therefore be related to factors such as profitability, improved service delivery, patient's satisfaction, and improved productivity. 
DOI: 10.14807/ijmp.v12i7.1457

Performance of government hospitals in Nigeria, which is hitherto affected by a multiplicity of interpersonal conflict, human resource inefficiency, lack of equipment and drugs, scarce resources, and differences in individual's goals as well as poor organizational goals can be improved through interpersonal conflict management.

\section{CONCLUSION}

This study focused on the place of interpersonal conflicts and healthcare delivery in government hospitals within Nigeria. It traced the causes of conflicts in healthcare industries as well as the place of interpersonal conflict management in work place productivity within the Nigerian healthcare industry. From the findings, the study concludes that collaborative approach of managing interpersonal conflict helps in reducing the mortality rate in Nigerian hospitals, and that when staff avoid the causes of conflict, they lay the foundation for resolving controversy or managing the situation, then improving the working relations in the hospital.

Finally, the study recommends that hospital managers should develop diverse but appropriate strategies to resolve and manage interpersonal conflicts; and efforts should be made by the hospital management to organize seminars/workshops on organizational conflict management from time to time for the employees. Again, there should be collaboration between management, departmental leadership, clerks, nurses, doctors and worker's representatives in running the affairs of the hospitals, and conflicting tendencies should always be avoided by workers for a more coordinated and minimal conflict work environment.

\section{REFERENCES}

Al-Hamdan, Z. (2009). Nurse Managers, Diversity and Conflict Management. Diversity in Health \& Care, 6, 31-43

Adebile, O. A., \& Thompson, O. O. (2012). Management of Organizational Conflict in Nigeria Polytechnics, an empirical study of the Federal Polytechnic Ede Sun State,”

International Journal of asian Social Science, Asian Economic and social society, 2(3), 229243.

Blake, R. R. \& Mouton, J. S. (1964). The managerial grid, Houston, Gulf.

Butler, A. G. (1973). Thesis Management: A Study in Organisational Conflict. Academy of Management Journal, 16, 84-101.

Chartered Institute of Personnel and Development (CIPD) Survey Report. (2008).

Leadership and the Management of Conflict at work, Retrieve from

http://www.cipd.co.uk.

Chukwuemeka, E. O., Ugwu, J., Enugu, O. T., \& Igwegbe, D. (2012). An Empirical Study of Industrial Conflict and Management in Nigerian Local Government System: A Study of Enugu State. International Journal of Human Resource Studies. 2(3), 1-21. 
Dann, D., \& Hornsayl, T. (1986). Towards a theory of Interdepartmental Conflict in Hotels, International Journal of Hospitality Management, 5(1), 23-28.

Deutsch, M., \& Coleman, P. (2000). The handbook of conflict resolution: Theory and practice. San Francisco: Jossey-Bass

Elsayed-Elkhouly, S. M. (1996). Styles of Handling Personal Conflict in Egypt, United States, Africa and the Gulf States. Cross Cultural Management: An International Journal, 3(1), 20-31.

Greer, L. L., \& Kleef, G. A. (2008). Power Distance, Conflict Resolution and Status Conflicts in Teams: How Do Team Power Dynamics Impact Conflict Resolution?. In: School of Organisation and Management, The University of New South Wales, IACM 21st Annual Conference Paper. Sydney, Australia

Hammond, K. R. (1965). New Directionsin Research on Conflict Resolution. Journal of Social Issues. 21, 44-66.

Henry O. (2009). Organizational Conflict and its effects on Organizational Performance. Research. Journal of Business Management, 2(1), 16-24.

Jehn, K. A. (1997). A qualitative analysis of conflict types and dimensions of organizational groups. Administrative Science Quarterly, 42, 530-557.

Kaitelidou, D. Et al (2012). Conflict Management and Job Satisfaction in Paediatric Hospitals in Greece.Journal of Nursing Management. 20(4), 571-578

Kelly, J. B. (2006). An Overview of Conflict. Dimensions of Critical Care Nursing. 25(1), 22-28.

Lawrence, P. R., \& Lorsch, J. W. (1967) Differentiation and Integration in Complex Organisations. Administrative Science Quarterly, 12, 1-47

Mullins, L. J. (2005). Management and Organisational Behaviour, 7th Edition, Essex: Prentice Hall.

Mukolwe, E., Korir, J., Buyeke, E., Wafula, M., \& Musyoki, J. (2015). Effects of Interpersonal Conflict on Organisational Performance in Selected Hotels in Kisistown, Kenya. African Journal of Hospitality, Tourism \& Leisure, 4(1), 1-15

Pondy, L. R. (1992). Reflections on organizational conflict. Journal of Organizational Behavior. 13, 257-261.

Rahim M. A. (2001). Managing Conflicts In Organisation. Westport, C. T. Quorom 3rdEdition.

Schramm-Nielsen, J. (2002). Conflict Management in Scandinavia. Department of Intemational Communication and Management, Copenhangan Business School, Denmark.

Skjørshammer, M. (2001). Conflict management in a hospitasl: designing processing structures and intervention methods. J. Manag. Med., 15(2), 156-166.

Tjosvold D, (1998). Cooperative and competitive goal approach to conflict: accomplishments and challenges. Applied Psychology: An International Review, 47(3), 285-342.

Wall, J. A., \& Callister R. R. (1995). Conflict and Its Management, Journal of Management, 21(3), 515-558. DOI: 10.1177/014920639502100306

Weihrich, H. (1992). Management: A Global Perspective, 11th Edition, Printice Hall, Englewood Cliffs. 
ISSN: 2236-269X

DOI: 10.14807/ijmp.v12i7.1457 